\title{
Feasibility of Laparoscopic Extraction of a Pulsating Fetus from the Fallopian Tube: A Case Report
}

\author{
Atef M. Darwish MD PhD \\ Department of Obstetrics and Gynecology, Woman's Health University Hospital, \\ Faculty of Medicine, Assiut University, Egypt \\ atef_darwish@yahoo.com
}

Abstract: This case report describes successful laparoscopic extraction of a viable tubal pregnancy with some technical tricks to control bleeding

\section{INTRODUCTION}

The frequency of ectopic pregnancy is increasing throughout the globe and it is the most life threatening emergency in first trimester of pregnancy (1). laparoscopic surgery is feasible and less expensive than open surgery for the treatment of tubal ectopic pregnancy (2). Laparoscopists are usually skeptic to perform salpingotomy for a pulsating tubal pregnancy due to expected excessive bleeding up to consenting the couple for slpingectomy if needed. In literature, it has been failed to find any publication on laparoscopic management of a pulsating ectopic tubal pregnancy.

\section{CASE PRESENTATION}

A healthy 21-year-old woman presented at 9 weeks of amenorrhoea with spotting and lowers abdominal pain. She had a previous history of one term pregnancies and one spontaneous abortion, and her current pregnancy occurred spontaneously. Her vital signs were stable, and physical examination revealed a slight pain in the right lower quadrant of the abdomen without rebound. Serum beta-human chorionic gonadotropin (beta-HCG) level was 12,237 IU/liter and hemoglobin level was $10.9 \mathrm{~g} / \mathrm{dl}$.

A transabdominal and transvaginal high resolution 2D ultrasound examination demonstrated a right adnexal ectopic pregnancy with a sac of $35 \mathrm{~mm}$ in diameter and a crown-rump length (CRL) of $27 \mathrm{~mm}$ with positive fetal heart rate, consistent with a fetal age of approximately 9 weeks and 5 days of amenorrhoea. No free fluid was noticed in the cul-de-sac. Positive fetal pulsations were confirmed by Doppler ultrasonography.

Based on ultrasound and Doppler findings (figure 1), the diagnosis of a living right tubal ectopic pregnancy was told to her. The patient was apprised of the diagnosis; treatment options were discussed. After obtaining informed consent, she was planned for a laparoscopy under general anesthesia.

Prior to laparoscopy by half an hour, the patient was given one gram of tranxamic acid IV. Diagnostic laparoscopy confirmed the diagnosis showing an enlarged congested uterus, an intact corpus luteum of pregnancy with marked vascularity in the right ovary and an intact right ampullary ectopic tubal pregnancy with extensive surface congestion.

As reminded by 2D and Doppler findings, excessive bleeding was expected. Since vasopressin is not allowed at our institution, injection of the mesosalpnix by $20 \mathrm{~mL}$ saline to compress the blood vessels at the bed was made. The tube was grasped by atraumatic delicate grasping forceps just proximal to the ectopic pregnancy. To avoid 
direct injury by the fine monopolar needle and excessive bleeding from the tubal wall, linear salpingotomy incision was superficially made using blend mode. Once the tubal wall was opened, another atraumatic grasping forceps was used to expel the tubal contents. The fetus as well as its sac was gently extruded with persistent fetal pulsation for a while till starting extraction of the future placenta where pulsations stopped (figure 2).

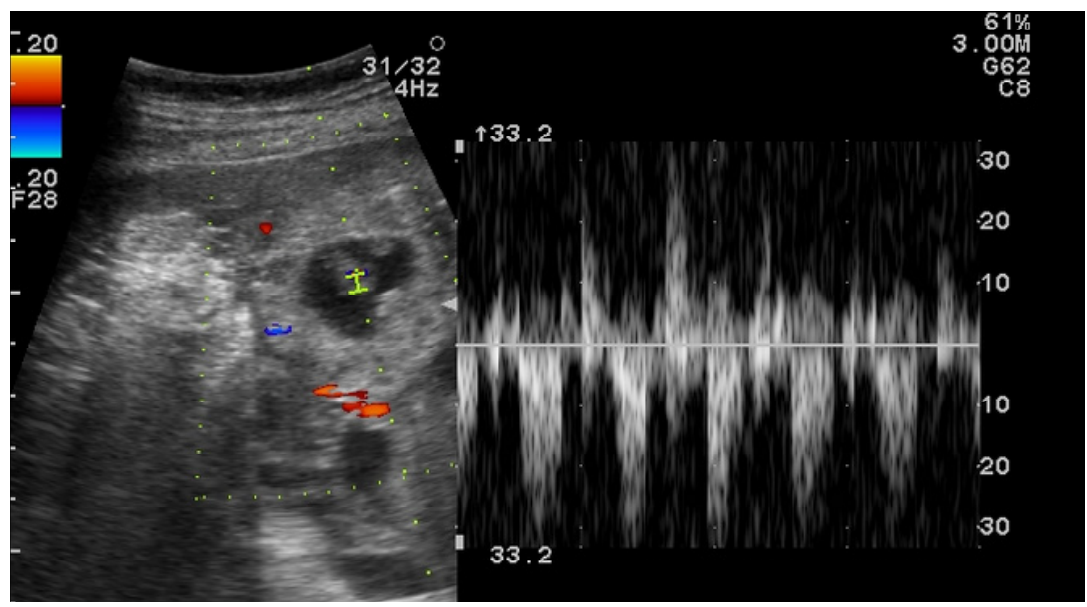

Fig1. Evidence of viability of ectopic pregnancy using Doppler ultrasound.

Using counter pressure, the rest of tubal contents were extracted. Hemostasis was confirmed. Repeated peritoneal toilet was done followed by leaving a copious amount of Ringer's solution and a drain. Postoperative course passed smoothly without compilations. The patient was discharged from the hospital within 4 hours. She was followed up after 2 weeks, including clinical examination, transvaginal ultrasound examination and plasmatic beta-HCG level.

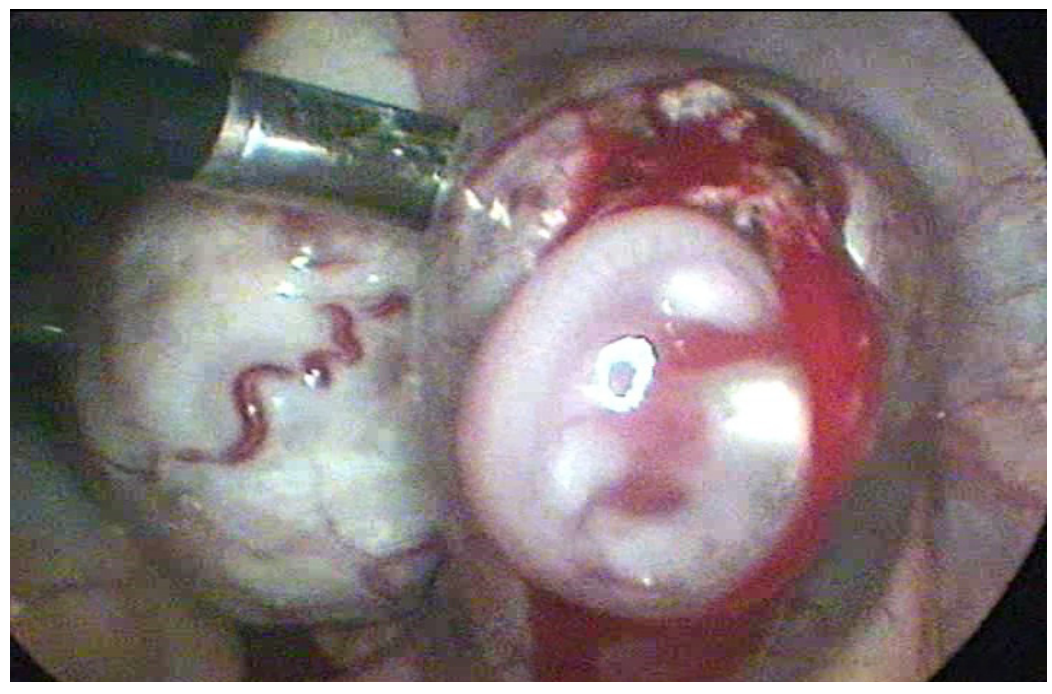

Fig2. Laparoscopic appearance of the fetus inside the sac after salpingotomy.

\section{DISCUSSION}

Despite the controversial role of endoscopic surgery in gynecologic practice versus other techniques like IVF/ ICSI, there is a universal agreement on the valuable role of laparoscopy in ectopic pregnancy $(3,4)$. 
As shown in the attached video tape, this is the first case report of laparoscopic extraction of a living fetus from the fallopian tube. The main message of this case report is to encourage laparoscopists to proceed for salpingtomy in all cases of ectopic pregnancy whenever the general condition of the patient is stable. Due to introduction of high resolution TVS and Doppler ultrasonography, many cases of ectopic pregnancy are diagnosed living prior to laparoscopy. In such cases, doctors suspect extensive uncontrollable bleeding so a clear consent of salpingectomy is written by the patient.

At our institution, we practice laparoscopic management of ectopic pregnancy since 1995. Extensive bleeding from the tubal wall as well as the placental bed was noticed if the pregnancy was viable. This case report shows practical steps to minimize bleeding. We started by IV administration of $1 \mathrm{gm}$ tranexamic acid prior to surgery by half an hour which was proved to minimize bleeding in different gynecologic and obstetric indications (5-7). Hydro injection of the mesosalpnix by saline was performed to induce temporary mechanical occlusion of the supplying blood vessels of the mesosalpnix. It was performed utilizing a fine needle introduced through the anterior abdominal wall directed to the mesosalpnix of the affected tube. The next step was grasping of the tube just proximal to the ectopic pregnancy to prevent propagation of trophoblastic tissue towards the uterus. This was done using a delicate atraumatic forceps to prevent endosalpingeal trauma. Salpingotomy was made on the antimesentric surface of the tube utilizing blend mode to minimize bleeding from the edges. Using all these steps would save many healthy tubes.

\section{CONCLUSIONS}

Living and pulsating ectopic tubal pregnancy is not a contraindication for laparoscopic extraction with precautions against excessive bleeding from future placental bed and tubal wall.

\section{CONSENT}

Written informed consent was obtained from the patient for publication of this case report and any accompanying images or video tape. A copy of the written consent is available for review by the Editor-in-Chief of this journal.

\section{COMPETING INTERESTS}

The author declares that he has no competing interests.

\section{REFERENCES}

1. Shaikh NB, Shaikh S, Shaikh F. A clinical study of ectopic pregnancy. J Ayub Med Coll Abbottabad. 2014 AprJun;26(2):178-81.

2. Hajenius PJ, Mol F, Mol BWJ, Bossuyt PMM, Ankum WM, van der Veen F. Interventions for tubal ectopic pregnancy. Cochrane Database of Systematic Reviews 1998;Issue 4. Art. No.: CD000324; D0I: 10.1002/14651858.CD000324.pub2.

3. Hajenius PJ, Mol F, Mol BW, et al. Interventions for tubal ectopic pregnancy. Cochrane Database Syst Rev 2007; CD000324.

4. Mol1 F, Mol1 BW, Ankum1 WM, van der Veen F, Hajenius P J. Current evidence on surgery, systemic methotrexate and expectant management in the treatment of tubal ectopic pregnancy: a systematic review and meta-analysis. Hum. Reprod. Update (2008) 14(4): 309-319.

5. Gultekin M, Diribas, K, Buru E,Gökçeoğlu MA. Role of a non-hormonal oral anti-fibrinolytic hemostatic agent (tranexamic acid) for management of patients with dysfunctional uterine bleeding. Clin Exp Obstet Gynecol. 2009;36(3):163-5. 
6. Peitsidis P, Koukoulomati A. Tranexamic acid for the management of uterine fibroid tumors: A systematic review of the current evidence. World J Clin Cases. 2014 Dec 16; 2(12): 893-898.

7. Lundin ES, Johansson T, Zachrisson H, Leandersson U, Bäckman F, Falknäs L, Kjølhede P. Single-dose tranexamic acid in advanced ovarian cancer surgery reduces blood loss and transfusions: double-blind placebo-controlled randomized multicenter study. Acta Obstet Gynecol Scand. 2014 Apr;93(4):335-44.

Citation: Atef M. Darwish MD PhD Department of Obstetrics and Gynecology, Woman's Health University Hospital, Faculty of Medicine Assiut University, Egypt, Feasibility of Laparoscopic Extraction of a Pulsating Fetus from the Fallopian Tube: A Case Report. ARJN Volume 2016; pp:1-4

Copyright (C) 2016 Atef M. Darwish MD PhD This is an open access article distributed under the Creative Commons Attribution License, which permits unrestricted use, distribution, and reproduction in any medium, provided the original work is properly cited. 